\title{
Integrating Quality Management Systems in Public Sector Financial Reporting Framework: a Developing Country's Nightmare
}

\author{
Owalla Wilfred $^{1}$ and Luanga Salome $A^{2}$ \\ ${ }^{I}$ Kisumu Polytechnic, Business Studies Department, P.O Box 143- 40100 Kisumu, Kenya; \\ ${ }^{2}$ Maseno University, Faculty of Education, Department of Education Management and Foundations Private \\ Bag, Maseno, Kenya:
}

\begin{abstract}
Good financial management is responsible for not only protecting, developing, using resources, pushing and maintaining economic growth and increasing income, but also managing effectively and efficiently all national resources."

Dr Dang VanThanh, president Vietnam Association of Accountants and Auditors

Public sector is the largest spender and employer in virtually every developing country and it sets the policy environment for the rest of the economy. It is presently challenged to provide high quality projects and services to its customers despite the difficult economic times leading to budgetary shortfalls. Demand for accountability of public resources has increased tenfold. Associated with this is the demand for efficient processes, consistently deployed and subject to continual improvement.

Public financial reporting is absolutely critical to improving the quality of public service outcomes. It affects how funding is used to address national and local priorities, the availability of resources for investment and the cost-effectiveness of public services. Also, it is more than likely that the general public will have greater trust in public sector organizations if there is strong financial stewardship, accountability and transparency in the use of public funds. It is important for governments to get it right because it impacts on a broad range of areas including:

Governance -accountability, comprehensiveness and transparency Operational management-value-for-money and budget management Fiduciary risk management - sustainability, ERM and oversight In addition, effective public financial reporting is important for decision making. Accurate financial information is often used as the mechanism to support decisions and ensure effective resource allocations.

In recent years there have been reforms in the public sector because quality of public sector accountability, effectiveness and efficiency in service delivery and transparency was thought to contribute to development and despite improvements in public financial management and tax administration, direct measures to reduce corruption and enhance provision of services rarely succeeded.

As organizations are growing and becoming more complex, they are confronted with a more dynamic and competitive environment and to maintain its survival, they must continuously respond to the environment. However, responding and ultimately reshaping the organization accordingly can be insufficient unless and until performance criteria is accounted for. Therefore it is imperative that for survival it is necessary for an organization to focus on quality improvement in order to survive. Quality Management Systems can be expressed as the organization structure, procedures, processes and resources needed to result into production of quality goods and services as per the expectations of the client in addition to being efficient, effective and economical.

There are different types of Quality Management Systems in use all over the world. The baseline for all these Quality Management Systems is that they emphasize on some common factors such as client/customer focus, involvement of all stakeholders, the systems are process and procedure based, a systems approach is adopted, mutual and beneficial relationship with stakeholders and most importantly emphasis on continual improvement. The study therefore explored the need for QMS integration into the public sector financial reporting framework. The researchers conducted a desk review of documents both at country level and international level using journals, books and reports.

The study concluded that it was important to include quality management systems into the public sector reporting framework

The study recommended that in future any reforms that are introduced into the public sector reporting framework should include quality management systems.
\end{abstract}

Key words: Public Sector Financial Reporting, Quality Management Systems, Operational Management, Governance, Fiduciary Risk Management 


\section{Introduction To Review}

The public sector is responsible for bringing together large amounts of resources to achieve a range of public goals. This responsibility comes with considerable complexity and expectations. Financial management is an important tool that helps the public sector take care of money in a systematic, efficient, transparent and legitimate way. Public sector financial management has three cornerstones which involve resource generation which is getting money, controlled delivery which is spending money and accountability involving reporting money (Graham 2011).

Historically, public sector financial management focused on ensuring that government revenue and expenditure were controlled in line with the overall approved budget lines. Governmental units were expected to strictly adhere to the laid down legal provisions and financial regulations as issued by the central government.

This approach to managing public finance has not delivered the key requirements of improving the quality and impact of public resources. In recent years, governments and donors have focused on wider issues through public expenditure and financial management reforms which include ensuring that limited resources are allocated to priority areas over the medium term, ensuring that all resources are planned and managed together i.e. recurrent and development, government and donor - so that they are all targeted at the same priority areas, increasing transparency in the use of public funds, introducing a performance focus in planning and budget management and ensuring that planning management and reporting of public funds meets international standards Public and Financial Handbook (2008).

Developing countries have attempted to introduce reforms in the public sector financial management. These reforms have majorly dealt with areas of resource generation, improved resource allocation with emphasis on sector wide approaches and fiscal discipline aimed at improving efficiency, effectiveness and value for money. Transparency, accountability and enhanced participation of stakeholders have also been issues that have been addressed.

Specific reforms that developing countries and emerging economies have implemented include the Medium Term Expenditure Framework (MTEF) which improves the links between planning and budgeting, Integrated Financial Management Information Systems (IFMIS), computerized financial management systems with emphasis on improving accuracy, timeliness, control, and management of public funds, strengthening management processes e.g. procurement reforms, payroll and personnel management reforms, bringing systems into line with international standards and audits and reforms to legal framework with introduction of new legislation and the strengthening the roles of oversight.

In order for financial management to occur and in order for public trust to be maintained, you need to make decisions based on good and accessible financial information. To get good and accessible financial information you need accounting. Public sector accounting is an activity with four key characteristics:

- It relies on a set of principles that guide the collection and reporting of financial information.

- Produces tangible outputs called financial statements which reduce all transactions into monetized terms and in so doing try to communicate trends in a government's financial performance.

- It is not an end in itself. It is a retrospective tool for managers to control the internal activities of the organization by allowing users to determine performance against plans.

- Is of interest to everyone (bureaucrats, politicians, and citizens) because it tells the story of how public money — everyone's money — is being spent.

The objective of financial reporting by the public sector entities are to provide information about the entity that is useful to the users of the report for accountability purposes and for decision making purposes. Financial reporting is not an end to itself. Its purpose is tp provide information that is useful to users of financial reports. The objectives of financial reporting are therefore determined by reference to the users and their information needs (public sector conceptual framework 2013).

Public sector accounting is the underlying foundation of the management cycle within public organizations. The need to have standards that protect the integrity of the accounting system is great, especially in the public sector where the users' interests are varied, and credibility is absolutely necessary and always under challenge. Additionally a standard reporting procedure and common reporting templates increase the legitimacy, transparency, and usefulness of the financial information collected by governments.

When financial information is collected and presented properly, it satisfies the public and empowers managers in the public services. It supports an informed and evidence based policy process.

Recent reforms to accounting and financial reporting have focused on the introduction of computerized financial management systems, which need to be accompanied by related improvements such as updating the legal framework, reforms to budget classification system and chart of accounts, making financial reports more user friendly as well as strengthening the process of holding line ministries accountable for performance (Public and Financial Handbook 2008).

Financial reporting systems have faced challenges in developing countries despite reforms in some of these countries. These challenges have resulted mainly from the use of cash based accounting procedures and 
manual or outdated computerized accounting systems, which has led to delays in the provision of financial reports as well as inaccurate financial data. The use of International Public Sector Accounting Standards (IPSAS) is not prevalent.

Cash accounting satisfies the annual budget-based interests of legislators and is simple in its presentation, but has a number of serious drawbacks, including:

- Failure to accurately represent the amount of resource usage. For instance, a large capital acquisition will distort expenditure upward in the first year but the usage of that asset will not be recognized in following years.

- Failure to take account of future commitments, guarantees, or other contingent liabilities. A liability will not be recognized until the cash is paid to settle the debt.

- Concentration on cash payments alone, sometimes resulting in an unnoticed deterioration in non-current assets, Public and Financial Handbook (2008).

\section{Statement Of Problem}

Governments of a number of jurisdictions throughout the world foreground financial reporting as the basis for reforms in public financial management. Transparent public financial management requires institutions and processes, both at central government and sub national level to generate better financial accountability and reporting to enhance effective allocation of resources [Mormont et al 1997, Kuppets 2001].

In order for any level of government to take responsibility for its actions, there must be clarity in its functional spending prioritization, its mechanism for appropriating funds and prioritizing and authorizing spending and ensuring that the spending is actually accounted for. Another critical aspect relates to timely and accurate reporting [Galera 2007].

The public sector being the largest spender and employer in virtually every developing country sets the policy environment for the rest of the economy. About one-sixth of the World Bank projects in recent years have supported public sector reforms because the quality of public sector accountability, effectiveness and efficiency in service delivery, transparency, etc is thought to contribute to development (World Bank 2008).

World Bank (2008) further found that although majority of countries with public sector reform programmes experienced improved performance in some dimensions, there were shortcomings in important areas and in overall coordination. It was noted that performance usually improved for public financial management, tax administration and transparency but did not usually improve with respect to civil service provision of services. It was also noted that direct measures to reduce corruption such as anti-corruption laws and commissions rarely succeeded.

Financial reporting systems have faced challenges in developing countries despite reforms in some of these countries (Public and Financial Handbook 2008). In Kenya the Auditor General has consistently passed adverse opinions on the quality of accounting records and financial reports (ICPAK 2013).

The purpose of this study therefore is to explore the need for integrating quality management systems into public sector financial reporting framework.

\section{Literature Review}

Today's competitive market is characterized by accelerating change, innovation and massive amounts of new information. Much of this rapid evolution in markets is backed by changing customer needs. Significant customer behavior and market changes happen almost overnight. As the pace of change accelerates, it becomes more difficult to maintain a stable relationship with suppliers, customers and even organization personnel. The quality of a product is defined according to the extent to which customer expectations, needs and demands are met. Customers choose products which maximize desired value (Kotler 1998). Customer satisfaction is important because it shows the organization whether they are doing the right thing or whether they are doing it the right way (Piskar 2003)

\section{Public Sector Financial Reporting Framework Introduction}

As organizations are growing and becoming more complex, they are confronted with a more dynamic and competitive environment and to maintain its survival, they must continuously respond to the environment. However, responding and ultimately reshaping the organization accordingly can be insufficient unless and until performance criteria is accounted for. Therefore it is imperative that for survival it is necessary for an organization to focus on quality improvement in order to survive.

The public sector is very wide as it includes all organizations that receive funding from public sources. Public sector usually has multiple goals which are all pursued together and it uses a variety of tools to achieve goals of the government. Therefore the way that the public sector uses must be transparent (Graham 2011). The public sector is responsible for bringing together large amounts of resources to supply a wide range of public goods. It is the largest spender and employer and in virtually every developing country, it sets the policy 
environment for the rest of the economy. Financial reporting is an important tool that helps the public sector to take care of resources in a systematic, efficient, transparent and legitimate way.

\section{Components of Public Sector Financial Reporting Framework}

Public sector financial reporting is critical to improving the quality of public service outcomes. It affects how funding is used to address national and local priorities, the availability of resources for investment and the costeffectiveness of public services. Also, it is more than likely that the general public will have greater trust in public sector organizations if there is strong financial stewardship, accountability and transparency in the use of public funds. It is important for governments to get it right because it impacts on a broad range of areas including:

Governance -accountability and transparency

Operational management - value-for-money and budget management

Fiduciary risk management - sustainability, ERM, and oversight

\section{Reforms in Public Sector Financial Reporting Framework in developing countries}

Effective public financial reporting is important for decision making. Accurate financial information is often used as the mechanism to support decisions and ensure effective resource allocations.

In developing countries, financial management systems have focused on improvements in fiscal discipline, improved allocation of resources, improved efficiency and effectiveness of expenditure and improving accountability and predictability with increased participation of stakeholders.

These reforms have been based on an approach called New Public Management (NPM) model which separates the functions of the principle who engages an agent to provide a particular service. Other approaches that are adopted include forward estimates whereby public institutions make budgets over a three year period and are given a high degree of flexibility and incentives to identify savings options themselves.

\section{Reasons why reforms are not succeeding as envisaged}

The empirical studies generally reveal that, due to the different factors, the design and implementation of governmental accounting reforms appear to be less successful and are diverging in an uncontrolled way. Some reforms have had unintended effects, either because of a misuse of the information or because insufficient attention was paid to the application of the reform. First, in some cases, the availability of output information has exposed bad performance of organizations. Rather than using the information to improve future performance, it then quickly becomes a superfluous information flow that is not properly used in decisionmaking or monitoring the organization. Secondly, reforms are often badly designed, so that they do not deliver on their promises. Schemes for measuring outputs do not always pay attention to their practical application (Christiaens and Rommel, 2008).

(Graham 2011) gives us a historical breakdown of financial management systems in developing countries. They were introduced in the colonial period and were effective in the 1960's and 1970's. From the 80 's onwards, these systems faced a number of constraints and the impact of these weaknesses was not addressed. Some of these include the fact that long term and medium term plans were not always based on a realistic resource envelope, new policies were introduced without sufficient analysis of their budgetary requirements, there was focus on processes and documents with little or no planning of outputs and services to be produced. There is also little emphasis on the alternative means neither of achieving objectives nor on cost, efficiency and effectiveness.

Among the other weaknesses he pointed out in budget implementation include insufficient accountability and transparency in the use of public funds, insufficient fiscal discipline with government systems. As appertains external resource inflows, public sector financial systems were developed before large inflows of external resources following independence which combined with lack of accountability has led to donors putting in place parallel systems.

The above weaknesses in PSFM are being addressed through reforms in developing countries which mainly focus on mandatory fiscal discipline, improving sector allocations and improving efficiency and effectiveness of expenditure.

Whilst these reforms have been initiated in many developing countries, a number of constraints have prevented from these reforms from reaching their full potential. These include political commitment to reform, lack of integration with the budget process, difficulties in defining appropriate performance indicators, system may not link budget and accounting systems and the government lacking the necessary systems and capacity to capture information. 


\section{Quality Management Systems \\ Introduction}

For an organization to function effectively, it has to determine and manage numerous linked activities. An activity or a set of activities using resources and managed in order to enable transformation of inputs into outputs can be considered a process.

A Quality Management System (QMS) can be expressed as the organization structure, procedures, processes, and resources needed to implement quality management. All these have to coordinate to direct and control an organization in order to continually improve the effectiveness and efficiency of performance. A QMS therefore defines processes which would result in production of quality products and services rather than detecting defective products or services after they have been produced. The QMS system should eventually ensure that the organization is able to produce goods or services as per the expectations of its customers or clients. In addition the resource use within the organization should be economical and efficient.

A good QMS will therefore strive to meet customer expectations, lower costs, reduce wastage, improve and standardize processes, increase market share, emphasize on continual improvement among numerous other benefits.

\section{Types of Quality Management Systems}

There are a number of methods for achieving quality improvement. They cover numerous aspects including product improvement, process improvement and people based improvement. The examples include:

Quality Function Deployment (QFD) where an attempt is made to transform user demands into design quality, deploy functions forming quality and deploy methods for achieving design quality into sub-systems and component parts and ultimately to specific elements of the manufacturing process (wikipedia.org/wiki/Quality_function_deployment).

The Japanese Kaizen which focusses basically on continuous improvement of processes in manufacturing, engineering and business management. It therefore refers to all activities that continually improve all functions, involves all employees and also strives to standardize and improve activities and processes. It also aims at eliminating waste (wikipedia.org/wiki/Kaizen).

Standard Process Control (SPC) is a method of quality control which uses statistical methods. It is applied in order to monitor and control a process hence ensuring that it is operating at its full potential. The key tools of the SPC method include control charts; focus on continuous improvement and experimental design (wikipedia.org/wiki/Statistical_process_control).

The Six Sigma is a method which combines established methods such as statistical process control, experimental design and the Failure Mode and Effects Analysis (FMEA). It seeks to improve the quality of process outputs by identifying and removing the causes of defects and minimizing variability in business processes. It has defined quantified value targets e.g. process cycle, time reduction, customer satisfaction, reduction in pollution, cost reduction and profit increase (wikipedia.org/wiki/Six_sigma)

Quality Circles (QC) is a group oriented approach to improvement. It comprises a volunteer group which is tasked to identify, analyze and solve work related problems in an attempt at improving the performance of the organization and to motivate and enrich the work of employees. They have the advantage of continuity (wikipedia.org/wiki/Quality_circle).

Plan, Do, Check, Act (PDCA) is a step management method used in business for control and for continuous improvement of processes and products (wikipedia.org/wiki/PDCA).

Business Process Re-engineering (BPR) is a management approach aimed at optimizing the workflows and processes within an organization and focuses on analyses and design of workflows and processes within the organization. BPR aims at helping organizations to fundamentally rethink how they do their work in order to dramatically improve customer service, cut operational costs and become world class competitors. It helps companies to radically restructure their organizations by emphasizing on a holistic focus of business objectives and how the processes are related to them and encouraging a full scale recreation of processes rather than iterative optimization of sub-processes. BPR is also known as business process redesign, business transformation or business process change management (wikipedia.org/wiki/Business_process_reingeneering).

Total Quality Management (TQM) which is a management strategy aimed at embodying awareness of quality in all organization processes. It is based on the premise that the quality of products and processes is the responsibility of everyone involved with the creation or consumption of products or services which are offered by an organization, requiring the involvement of management, workforce, suppliers and customers in an attempt to meet or exceed customers' expectations. It uses strategy, data, effective communication and the involvement of all levels of employees in order to integrate quality discipline into the culture and activities of the organization. It is customer focused; process centered and is an integrated system. It also emphasizes on continual process improvement, fact based decision making and effective communication. 
ISO 9001, the standard defining Requirements for Quality Management Systems, serves as the basis for a majority of quality management systems. The ISO 9001 standard provides sound and flexible baseline quality requirements intended to achieve predictable outcomes, and consistent customer satisfaction in the execution of projects. A QMS based on the ISO 9001 standard is much more than an incidental focuses on meeting customer requirements; it is an intentional and structured approach to exceeding customer requirements (http://www.iso.org).

Quality management systems structured around ISO 9001 requirements are based upon the following eight quality management principles (International Organization for Standardization), customer focus, leadership, involvement of people, process approach, systems approach to management, continual improvement, factual approach to decision making, and mutual beneficial relationships.

\section{Common issues addressed by the QMS systems}

All these QMS address some of the key common components of quality management. These components include customer focus, involvement of all stakeholders, the management system should be process and procedure based, emphasis on continual improvement, systems approach given and there is a mutual and beneficial relationship between both the organization and its stakeholders.

\section{Methodology}

The researchers conducted a desk review of documents both at country level and at international level i.e. an external desk review. Data collection was mainly dependent on secondary data sources. The researcher also conducted interviews with selected key informants and groups as well as interviewing stakeholders where appropriate.

This desk review was developed to address the research questions as outlined in the appendices (appendix 2). The desk review expanded on the questions thus providing a wider and fuller interpretation of the two variables namely public sector financial reporting and quality management systems.

The documents used for the review included books, journals, reports, etc. as was found appropriate. Data triangulation was achieved by interviewing a range of stakeholders at different levels from a variety of institutions and reviewing a wide range of documents.

\section{Challenges And Limitations}

The challenges faced by this review included the limitations of counterfactuals, constraints in identifying sound basis for comparison between the few public sector entities that had applied QMS systems as at before application and after the application. There were also possible biases of the key informants and stakeholders. The researchers sought to minimize possible biases through triangulation of the methods and data wherever feasible. There was also lack of baseline and end line data for most these indicators at output and outcome levels. The researchers encountered limited availability of monitoring data and reports were usually delayed hence not useful.

\section{Discussion Of Findings}

\section{Table 1: Components of QMS System relevant to Public Sector Financial Reporting}

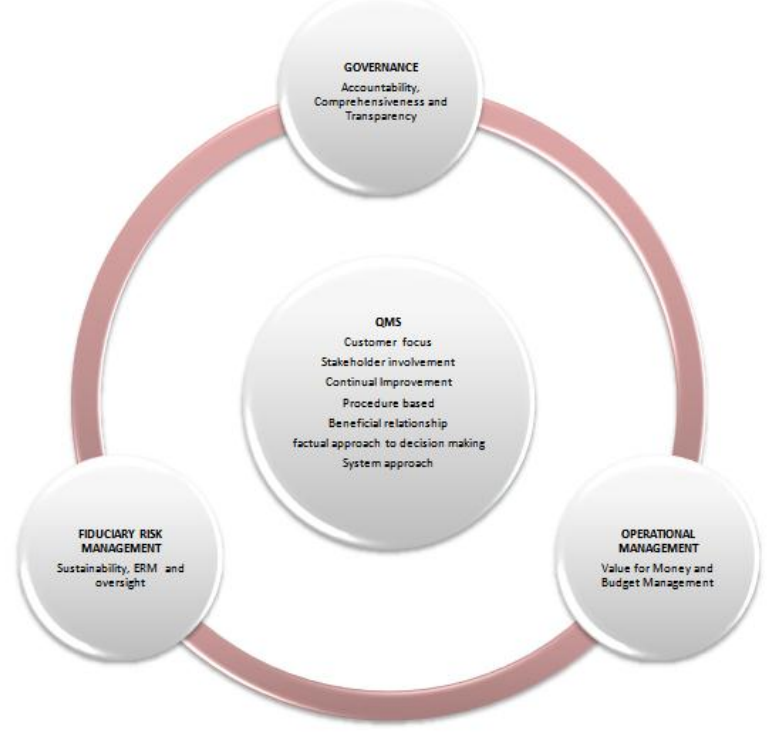




\section{ACCOUNTABILITY}

Accountability is answerability, blameworthiness, liability and expectation of account giving. In governance, accountability has expanded beyond the basic definition of being called to account for ones actions. It is described as an giving relationship between individuals. Accountability cannot exist without proper accounting practices (en.wikipedia.org/wiki/accountability).

As increasing number of governments and intergovernmental organizations produce financial statements on an accrual basis of accounting in accordance with IPSAS or IPSAS similar standards. This information is considered useful both for accountability and for decision making purposes and reports prepared in this manner allows users to assess accountability for all resources. The entity controls the deployment of controls.

The current economic crises and scarce financial constraints experienced by many governments has underscored the need for governments to transparently report all their assets and liabilities (delliotte 2013).

The International Federation of Accountants (IFAC) and Chartered Institute of Public Finance and Accountancy (CIPFA), have issued a consultative draft on an international framework on governance in the public sector. The draft framework asserts that "public sector entities need to demonstrate that they have delivered their stated commitments, requirements and priorities and have used public resources effectively in doing so." And so recommend reporting publicly at least annually, performance information and the accompanying financial statements. The framework recommends financial statements prepared in accordance with IPSAS (IFAC 2013).

Hamisi (2012) acknowledges that there are fundamental problems that currently inhibit efficiency and effectiveness of GoK'sfinancial functions. These include poor performance of basic financial functions, poor supervision, inadequate financial information and decision support, poor staff motivation and attitudes in accounting and accountability.

Some of the qualities propagated by QMS system can effectively address these issues. Poor performance of basic financial functions can be effectively addressed by being user focused and identifying and achieving user needs. Having a procedure based approach as well as a systems approach will be effective in addressing poor performance. Beneficial relationships can effectively address poor staff motivation and attitudes to accounting and accountability.

IPSASB has published new Recommended Practice Guideline (RPG) providing guidelines on preparing and presenting financial statement discussion and analysis of financial statements of public sector entities. This RPG outlines that financial discussion and analysis should include an overview of the entities operations and the environment in which it operates, information about the entity's financial statements including significant changes and trends in an entity's financial position, financial performance and cash flows, a description of the entity's principal risks and uncertainties that affect it financial performance and cash flows, an explanation of the changes in these risks and uncertainties since the last reporting date and its strategies for bearing and mitigating these risks and uncertainties (IASB 2013).

Comprehensiveness and transparency is another aspect of public sector financial management. The public sector industry is rapidly transforming and many reforms are taking place to anticipate challenges as they arise. Public sector organizations need to make decisions based on well thought out information.

Comprehensiveness is generally taken to mean provision of stakeholders with information on all facts and considerations relevant to particular policy decisions about a public sector institution. Comprehensiveness involves measurement especially in the context of spending. In testing for the value of comprehensiveness, various output measures can be of use. This includes budget control which is sometimes characterized by political considerations especially to reward the faithful and punish perceived enemies.

There is therefore a good basis to apply quality measures especially where there are competing interests for the same expenditure. The budget controller would want to select projects or programs ranking high in a priority scale and to prevent the effect of bias he would want to focus on the customer demand and involvement of stakeholders in setting priorities.

Transparency means being open to the public about the structure and function of the governmental organization, the policy intentions and the public sector accounts and projections (Koppits 1998). It involves providing ready access to reliable, comprehensive, timely, understandable and internationally comparable information on governmental activities.

The pillars of transparency involve clarity of roles and responsibilities, structure and functions of government, responsibilities within the government, government bodies and the rest of the economy, an open budget process involving preparation, execution, monitoring, realism of estimates and sustainability; public availability of information and the assurance of integrity including quality of fiscal data, internal oversight and external scrutiny. 
Transparency is important because it promotes openness of government structure, functions and policy intentions, promotes citizens' rights to information, improves decision making and meets international obligations.

These can also be effectively enhanced using the QMS variables of customer approach, involvement of stakeholders, continual improvement and a mutual beneficial relationship.

\section{Value for Money}

\section{Operational Management}

Information explosion and communication revolution of the 90's have permeated every level of the society and now for the vast majority of the ordinary citizens 'knowledge is power'. Governments are being reinvented. The following have been observed as signs of change i.e. financial stress, increasing demand for public accountability, demands for the government to be more responsive to government needs, demand for public sector agencies to be more responsive to government needs, pressure of globalization and information technology commercialization, corporatization and commercialization (pearson 2000).

The government is in business of obliging individual clients to contribute to public purposes as well as providing services to clients and therefore it is necessary to think about what clients would value in obligation encounter as well as service encounter. A value driven service means developing and augmenting services to resonate with citizens, authorities and overseers (moore 2006).

The concept of value for money in everyday life is easily understood i.e. not paying more for a good or service than its quality of availability justifies. In relation to public spending, it implies concern with economy (cost minimization), efficiency (output maximization) and effectiveness which is the full attainment of intended results (glendinning 1998).

\section{Budget Management}

Budget Credibility: profitability is a key concept in the private sector whereas budget is a key fiscal document. Many budgets are created with little regard for spending realities as budgets are changed in execution phase without the spirit of the original plan. Considerable effort has been made to have developing countries improve budget planning but these better budgets did not result better spending. An effective budget mainly pursues three objectives namely maintaining fiscal discipline, allocating resources in accordance with policy priorities and efficiently delivering services or value for money (www.freebalance.com).

It is important for the budget to focus on the client, addressing the prime needs of both the internal and external stakeholders. In addition to this, structured procedures and processes should be adopted in planning the budget as well as determining policy priorities. This will prevent political considerations, abuse of office, cases of misappropriation and misallocation of resources among others.

There should be a consistent and sustained effort at building continuous improvement through a structured process of identifying and responding to changing local requirements both of budget prepares and other stakeholders. There is also a need for continuous skill management and improvement in the quality of the workforce. This should include continuous sensitization and education of the stakeholders especially to the members of public. There then should be a systematic manner in which there can be some assurances that the improvement in the practices and procedures leading to development, transfer of knowledge and skills equally benefit the internal and external stakeholders. There therefore should be put in place a quality assurance mechanism and a quality improvement mechanism.

Comprehensiveness and transparency is another aspect of public sector financial management. The public sector industry is rapidly transforming and many reforms are taking place to anticipate challenges as they arise. Public sector organizations need to make decisions based on well thought out information.

Comprehensiveness is generally taken to mean provision of stakeholders with information on all facts and considerations relevant to particular policy decisions about a public sector institution. Comprehensiveness involves measurement especially in the context of spending. In testing for the value of comprehensiveness, various output measures can be of use. This includes budget control which is sometimes characterized by political considerations especially to reward the faithful and punish perceived enemies.

There is therefore a good basis to apply quality measures especially where there are competing interests for the same expenditure. The budget controller would want to select projects or programs ranking high in a priority scale and to prevent the effect of bias he would want to focus on the customer demand and involvement of stakeholders in setting priorities.

Transparency means being open to the public about the structure and function of the governmental organization, the policy intentions and the public sector accounts and projections (Koppits 1998). It involves providing ready access to reliable, comprehensive, timely, understandable and internationally comparable information on governmental activities. 
The pillars of transparency involve clarity of roles and responsibilities, structure and functions of government, responsibilities within the government, government bodies and the rest of the economy, an open budget process involving preparation, execution, monitoring, realism of estimates and sustainability; public availability of information and the assurance of integrity including quality of fiscal data, internal oversight and external scrutiny.

Transparency is important because it promotes openness of government structure, functions and policy intentions, promotes citizens' rights to information, improves decision making and meets international obligations.

These can also be effectively enhanced using the QMS variables of customer approach, involvement of stakeholders, continual improvement and a mutual beneficial relationship.

\section{SUSTAINABILITY}

Operating in an environmentally, socially and economically sustainable manner is one of the most urgent challenges facing organizations today. Issues such as climate change, overconsumption of finite natural resources and rapidly increasing destruction of earth's ecosystems will drive fundamental shifts and economy. It is therefore increasingly important for the organization to understand and respond both to the manner in which these issues will affect their own continuity and long term success and how they can help the society as a whole in meeting the challenges faced (hopwood 2008).

Hopwood (2008) further contend that accounting processes and practices have a key role to play in helping the organization to develop more sustainable operations that are a necessary part of this response. Such practices enable the systematic identification of the economic, social and environmental costs and benefits of organizations strategies and actions. To fulfill its potential in these important roles, accounting practice needs to develop from its traditional focus on the economic front and also encompass the social and environmental dimensions of organization strategies and actions.

Traditional business, financial and accounting practices have tended to focus solely on financial or economic outcome of business activities. In the commercial sector these practices have sought to help to maximize financial returns in the form of increased profit and shareholder value. More recently however, a growing recognition of all potentially significant social and environmental impacts of human action has led to many organizations to also consider social and environmental outcome of their activities.

Where these outcomes were previously treated as externalities, without considering their longer term impact on the organization itself, they are now progressively being brought into the decision making process. From this perspective, sustainability is seen as an increasingly urgent strategic issue that poses significant challenges to business, the public sector and the society as a whole.

\section{Conclusion}

As was noted earlier, the public sector is the largest spender and employer in the economy of developing countries thereby also leading to policy shifts, has led to accountability in public resources.

Reforms have been introduced in the public sector financial management and public sector reporting framework because of the belief that improvement in public sector financial reporting will contribute to economic development.

However despite the introduction of reforms in the public sector reporting framework, especially in developing countries, these reforms have generally not succeeded. As public organizations are growing and becoming more complex and dynamic, coupled with changing economic environment, focus has naturally shifted to sustainability. It has become necessary to be customer focused in order to respond to all these changing circumstances. Therein lies the advantages of quality management systems.

There are various types of quality management systems. The study found a common baseline among these quality management systems. These included: customer focus, involvement of stakeholders, management systems being procedure based, emphasis on continual improvement, a systems approach as well as ensuring that there is a beneficial relationship between the organization and its stakeholders.

The study therefore concluded that in order that the reforms in the public sector financial reporting to impact as intended it was necessary to include quality management systems into the reporting framework.

The relationship between the two variables is shown in the table below: 
Table 2: Relationship between Components of Financial Reporting and QMS

\begin{tabular}{|c|c|c|}
\hline COMPONENT & TECHNICAL QUALITY & QMS QUALITY \\
\hline \multicolumn{3}{|l|}{ GOVERNANCE } \\
\hline ACCOUNTABILITY & $\begin{array}{ll}\text { - } & \text { Financial Reports } \\
\text { - } & \text { Analysis and Reconciliation of } \\
\text { - } & \text { Financial Information } \\
\text { - } & \text { Preparation of Periodic Reports } \\
& \text { Statements } \\
\text { - } \quad \text { External Audit }\end{array}$ & $\begin{array}{ll}\text { - } & \text { User focus } \\
\text { - } & \text { Procedure based } \\
\text { - } & \text { Systems approach } \\
\text { - } & \text { Beneficial relationship }\end{array}$ \\
\hline $\begin{array}{l}\text { COMPREHENSIVENESS } \\
\text { AND TRANSPARENCY }\end{array}$ & $\begin{array}{ll}\text { - } & \text { Capturing and Recording Information } \\
\text { - } & \text { Record keeping } \\
\text { - } & \text { Timely Document Retrieval } \\
\text { - } & \text { Presentation of Reports } \\
\text { - } & \text { Clarity or Roles and Responsibility }\end{array}$ & $\begin{array}{ll}\text { - } & \text { Stakeholder involvement } \\
\text { - } & \text { Procedure based } \\
\text { - } & \text { System approach } \\
\text { - } & \text { Continual improvement }\end{array}$ \\
\hline \multicolumn{3}{|c|}{ OPERATIONAL MANAGEMENT } \\
\hline VALUE FOR MONEY & $\begin{array}{ll}\text { - } & \text { Efficiency } \\
\text { - } & \text { Effectiveness } \\
\text { - } & \text { Economy }\end{array}$ & $\begin{array}{l}\text { - } \quad \text { Factual approach to decision } \\
\text { making } \\
\text { - } \quad \text { Procedure based } \\
\text { - } \quad \text { Systems based } \\
\text { - } \quad \text { User focus } \\
\text { - } \quad \text { Stakeholder involvement }\end{array}$ \\
\hline BUDGET MANAGEMENT & $\begin{array}{ll}\text { - } & \text { Budget Credibility } \\
\text { - } & \text { Budget Preparation } \\
\text { - } & \text { Budget Implementation }\end{array}$ & $\begin{array}{ll}\text { - } & \text { User focus } \\
\text { - } & \text { Stakeholder involvement } \\
\text { - } & \text { Procedure based } \\
\text { - } & \text { System based } \\
\text { - } & \text { Continual improvement }\end{array}$ \\
\hline \multicolumn{3}{|c|}{ FUDICIARY RISK MANAGEMENT } \\
\hline SUSTAINABILITY & $\begin{array}{l}\text { Environmental Accounting } \\
\text { - } \quad \text { Social Responsibility Accounting }\end{array}$ & $\begin{array}{ll}\text { - } & \text { User focus } \\
\text { - } & \text { Stakeholder involvement } \\
\text { - } & \text { Continual improvement } \\
& \text { Beneficial relationship }\end{array}$ \\
\hline $\begin{array}{ll}\text { ENTERPRISE } & \text { RISK } \\
\text { MANAGEMENT } & \end{array}$ & $\begin{array}{ll}\text { - } & \text { Risk management } \\
\text { - } & \text { Risk analysis } \\
\text { - } & \text { Risk mitigation }\end{array}$ & $\begin{array}{ll}\text { - } & \text { Stakeholder involvement } \\
\text { - } & \text { System based } \\
\text { - } & \text { Procedure based } \\
\text { - } & \text { Beneficial relationship }\end{array}$ \\
\hline OVERSIGHT & $\begin{array}{ll}\text { - } & \text { Controls } \\
\text { - } & \text { Compliance } \\
\text { - } & \text { Oversight }\end{array}$ & $\begin{array}{ll}\text { - } & \text { Stakeholder involvement } \\
\text { - } & \text { User focus } \\
\text { - } & \text { Procedure based } \\
\text { - } & \text { System based }\end{array}$ \\
\hline
\end{tabular}

\section{Recommendations}

The study recommends that it is imperative that national and subnational governments especially in developing countries do introduce quality management systems into reforms that are being introduced into the public sector financial reporting framework.

\section{Recommendations for further research}

Further research should be undertaken on public sector financial institutions that have implemented quality management systems to study the impact of the quality management system.

Research could also be done on the above mentioned organizations but looking at the different types of quality management systems deployed in order to assess the impact of the different types of quality management systems.

\section{Appendices}

\section{Appendix 1: References}

[1] ACCA 2010 'Improving Public Sector Financial Management in Developing Countries and Emerging Economies'

[2] Hopwood G. A., Inerman J., Fries J. 2008 Accounting for Sustainability: Practical Insights

[3] Christiaens, Johan, and Jan Rommel. 2008. Accrual Accounting Reforms: Only for Business-like Parts of Governments. Financial Accountability and Management 24(1): 59-75.

[4] Deloitte 2013 'IPSAS in your pocket'

[5] En.wikipedia.org/wiki/accountability accessed on $14^{\text {th }}$ August 2013

[6] Glendinning R., 1988, The Concept Value for Money” International Journal of Public Sector Management Volume 1

[7] Graham A. November 2011 'Public Sector Financial Management for Managers' Kingston, Canada

[8] Hamisi S. K. 2012 "Factors affecting the Implementation of IPSAS in Kenya" School of Business, University of Nairobi.

[9] IASB published Guidance on Public Sector Financial Statement Discussion and Analysis July 2013

[10] ICPAK Position Paper on Fundamentals of Financial Management 2013 
[11] IFAC June 2013, "Public Sector Governance Framework Proposed"

[12] International Standard ISO 9001 Quality Management Systems - Requirements

[13] Kopits G., Craig J., 1998 'Transparency in Government Operations' IMF Washington DC

[14] Moore M., 2006, "Recognizing Public Value: The Challenge of Measuring Performance in Government" kernel School of Government, Havard University

[15] Pearson P., 2000, "Contemporary Issues in Public Sector Accountability" paper presented to conference $23{ }^{\text {rd }}$ February 2000 Perth, Office of the Auditor General, Western Australia

[16] Piskar F., 2003 The Impact of Quality Management System, ISO 9000 on Customer Satisfaction of Slovenian Companies

[17] 'Public Expenditure and Financial Management Handbook', Macro economic and Financial Management Institute of Eastern and Southern Africa, December 2008

[18] Public Sector Reforms what works and why: An IEG Evaluation of World Bank Support 2008

[19] Vokura R. J. 2003 'Using the Baldridge Criteria for Personal Quality Improvement, Industrial Management and Data Systems

\section{Appendix 2: Aim Of The Review}

To explore the need for integrating QMS Systems in Public Sector Financial Reporting

\section{Objectives Of The Review}

1. Explain the types and key issues of a QMS system

2. Illustrate the components of Public Sector Financial Reporting

3. Assess the extent of reforms in Public Sector Financial Reporting framework developing countries

4. Examine reasons why these reforms are not succeeding to achieve their intended objectives

5. Establish how QMS could be included in the Public Sector Financial Reporting Framework

\section{review questions}

1. What are the types and key issues addressed by a QMS system?

2. What are the main components of Public Sector Reporting Framework?

3. What reforms have currently taken place in Public Sector Financial Reporting Framework?

4. Why are these reforms not working as envisaged?

5. How can the integration of QMS improve the Public sector Reporting Framework? 